\section{First insights into the genetic diversity of Mycobacterium tuberculosis strains in Salvador, Bahia State, Brazil}

\author{
Primeiro ensaio sobre diversidade genética das \\ cepas de Mycobacterium tuberculosis em \\ Salvador, Bahia, Brasil
}

\author{
Aída Cristina do Nascimento Silva 1 \\ Lucilaine Ferrazoli 2 \\ Vera Simonsen 2 \\ Joice Neves Reis 3 \\ Susan Martins Pereira 4 \\ Theomira Mauadie de Azevedo Carmo 1 \\ Eduardo Luiz Andrade Mota 4 \\ Mitermayer Galvão Reis 1
}

\section{Introduction}

Tuberculosis (TB) is a global public health issue, with 9.27 million new cases and 1.3 million deaths worldwide in 2007 1. Brazil ranks among the 22 countries with the highest incidence rates of tuberculosis, with 100,000 new cases of TB being registered annually. In 2006, 6,500 cases of TB were registered in the State of Bahia, which is currently ranked as the third state in absolute numbers of cases in Brazil. Of these cases, 2,300 occurred in the city of Salvador 2. Recently, molecular techniques have been used to explain the epidemiological aspects of TB, contributing towards improving understanding of transmission dynamics that drive the disease 3 .

To date, no studies have been carried out on the epidemiologic and genetic diversity of circulating Mycobacterium tuberculosis in Salvador, a city in the Northeast Region of Brazil, where the incidence of this disease is high. The aim of the present study was to describe the genetic population structure of M. tuberculosis circulating in Salvador.

\section{Methodology}

\section{Patients}

This study included confirmed TB cultures from patients over 18 years of age diagnosed between March and June 2008 and receiving care at the 
Otavio Mangabeira Specialist Hospital (HEOM/ SESAB), a referral unit for pneumopathies situated in the city of Salvador. The research project was approved by the National Health Surveillance Agency/Ministry of Health in Brasília, and by the ethics committee of the Collective Health Institute, Federal University of Bahia.

\section{Bacterial isolates}

The M. tuberculosis isolates were collected and processed from sputum samples in accordance with the protocol established by the Department of Mycobacteriology of the Central Laboratory of Public Health "Professor Gonçalo Muniz" (LACEN-BA) 4.

\section{IS6110-RFLP analysis and definitions}

The clinical isolates of $M$. tuberculosis were typed using restriction fragment length polymorphism (IS6110-RFLP) analysis in accordance with the standardized protocol described by van Embden et al. 5. The genetic profile of each strain was analyzed and visualized with GelCompar II version 4.0 (Applied Maths, Kortrijk, Belgium) using M. tuberculosis 14323 as the reference strain. All the strains with a similarity coefficient of > 90\% were considered part of a "family". Within the molecular typing system, cluster strains were defined as being those which were found to have the same RFLP pattern (number of bands and position of the fragment) in two or more isolates of M. tuberculosis. Isolates which were found to have RFLP patterns distinctly different from the other patterns identified were considered to be non-clusters 3 . Isolates forming part of a cluster pattern were defined as representing a recently acquired infection and standard non-cluster isolates were defined as representing reactivation of an infection acquired in the past ${ }^{3}$.

\section{Data analysis}

Exploratory data management was performed using Stata version 7.0 (Stata Corp., College Station, USA). Prevalence ratios (PR) and their respective $95 \%$ confidence intervals $(95 \% \mathrm{CI})$ were calculated.

\section{Findings}

\section{Analysis of patient characteristics and} associated factors

Fifty six patients whose sputum cultures tested positive for M. tuberculosis were enrolled in this study between March and June 2008,. Of this total, the majority $(71.43 \%)$ were male and over 30 years of age (68.75\%) (Table 1). Regarding ethnic background, most of the patients $(80 \%)$ classified themselves as non-white. With respect to education, $63.89 \%$ of the patients were illiterate or had failed to complete primary school. A quarter of the patients did not reside in Salvador and $23.4 \%$ had been submitted to a category III treatment regimen [indicated in Brazil for the treatment of cases in which previous treatment with regimens I, IR (recurrence after cure) and II, has failed].

A positive association was found between the formation of cluster patterns and the following factors: being male ( $\mathrm{PR}=1.87$; 95\%CI: 0.62-5.63), age $>30$ years $(\mathrm{PR}=1.67$; 95\%CI: 0.54-5.11), being self-classified as non-white $(\mathrm{PR}=3.00 ; 95 \% \mathrm{CI}$ : 0.46-19.35), being illiterate or having failed to complete primary school (PR = 1.70; 95\%CI: 0.55 5.17); not living in Salvador ( $\mathrm{PR}=1.67$; 95\%CI: $0.69-4.00$ ); having been submitted to a category III treatment regimen for tuberculosis $(\mathrm{PR}=1.31$; 95\%CI: 0.51-3.36). The associations found were not statistically significant.

\section{RFLP analysis}

Of the 56 patients analyzed, 41 of the isolates (73.21\%) had single patterns and 15 (26.78\%) had group patterns. Overall, all the isolates had 2-16 copies of IS6110-RFLP and $10.7 \%$ of all samples analyzed had six or fewer copies of this repetitive element. Fifteen isolates formed 6 distinct clusters denominated CL I, CL II, CL III, CL IV, CL V and CL VI. Each cluster was composed of 2 isolates except for CL V, which was composed of 5 isolates (Figure 1).

\section{Discussion}

This is the first exploratory study conducted in Bahia with the aim of describing the genetic population structure of $M$. tuberculosis, as regards recent infection or reactivation. The principal finding refers to the fact that $26.78 \%$ of isolates formed cluster patterns, suggesting recent transmission of TB in this group of patients. This proportion is slightly higher than the findings of studies conducted in Rio de Janeiro using similar methodology (19\%) 6 and similar to the results of studies carried out in isolates in Porto Alegre (State of Rio Grande do Sul) and São Paulo 3,7 which amounted to $29.1 \%$ and $33 \%$, respectively. In the present study, the percentage of cluster strains found was slightly lower than those reported in studies conducted in France (35\%) 8 and San Francisco (40\%) 9. 
Bivariate analysis of the association between the co-variables and restriction fragment length polymorphism (RFLP) pattern (cluster or non-cluster) of Mycobacterium tuberculosis isolates from patients infected with tuberculosis (TB). Salvador, Bahia State, Brazil.

\begin{tabular}{|c|c|c|c|c|c|c|c|}
\hline \multirow[t]{2}{*}{ Predictive variables } & \multicolumn{2}{|c|}{ Cluster $(n=15)$} & \multicolumn{2}{|c|}{ Non-cluster $(n=41)$} & \multicolumn{2}{|c|}{ Total $(N=56)$ * } & \multirow[t]{2}{*}{$\mathrm{PR}(95 \% \mathrm{Cl})$ ** } \\
\hline & $\mathbf{n}$ & $\%$ & n & $\%$ & $\mathbf{n}$ & $\%$ & \\
\hline \multicolumn{8}{|l|}{ Sex } \\
\hline Male & 14 & 35.00 & 26 & 65.00 & 40 & 71.43 & $1.87(0.62-5.63)$ \\
\hline Female & 3 & 18.75 & 13 & 81.25 & 16 & 28.57 & 1.00 \\
\hline \multicolumn{8}{|l|}{ Age (years) } \\
\hline$>30$ & 11 & 33.33 & 22 & 66.67 & 33 & 68.75 & $1.67(0.54-5.11)$ \\
\hline $18-29$ & 3 & 20.00 & 12 & 80.00 & 15 & 31.25 & 1.00 \\
\hline \multicolumn{8}{|l|}{ Self-reported ethnic background } \\
\hline Non-white & 12 & 42.86 & 16 & 57.14 & 28 & 80.00 & $3.00(0.46-19.35)$ \\
\hline White & 1 & 14.29 & 6 & 85.71 & 7 & 20.00 & 1.00 \\
\hline \multicolumn{8}{|l|}{ 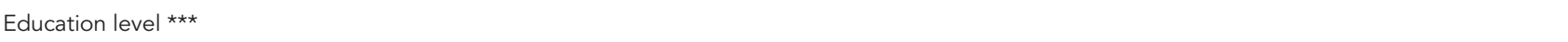 } \\
\hline Illiterate/Did not finish primary school & 9 & 39.13 & 14 & 60.87 & 23 & 63.89 & $1.70(0.56-5.17)$ \\
\hline $\begin{array}{l}\text { Completed primary school/Attended at least some high } \\
\text { school }\end{array}$ & 3 & 23.08 & 10 & 76.92 & 13 & 36.11 & 1.00 \\
\hline \multicolumn{8}{|l|}{ Residence in Salvador } \\
\hline No & 5 & 41.67 & 7 & 58.33 & 12 & 25.00 & $1.67(0.69-4.00)$ \\
\hline Yes & 9 & 25.00 & 27 & 75.00 & 36 & 75.00 & 1.00 \\
\hline \multicolumn{8}{|l|}{ Treatment regimen } \\
\hline Category III (therapeutic failures) & 4 & 36.36 & 7 & 63.64 & 11 & 23.40 & $1.31(0.51-3.36)$ \\
\hline Category I (new cases of TB) & 10 & 27.78 & 26 & 72.22 & 36 & 76.60 & 1.00 \\
\hline
\end{tabular}

PR: prevalence ratio; $95 \% \mathrm{Cl}$ : 95\% confidence interval.

Note: missing data - age (missing in 8 cases); self-reported ethnicity (missing in 21 cases); education level (missing in 20 cases); residence in Salvador (missing in 8 cases); treatment regimen (missing in 9 cases).

* Total varies in accordance with availability of data;

** PR and $95 \% \mathrm{Cl}$ were calculated after excluding missing data;

*** Classification adopted in the registers of the notification and investigation of cases of tuberculosis (Departamento de Informática do SUS. Sistema de Informações de Agravos de Notificação. http://www.datasus.gov.br).

The proportion of non-cluster strains was $73.21 \%$, suggesting the need to improve TB control, promoting preventive actions against reactivation. In Brazil, recent studies 3,7 show similar findings. Around $70 \%$ of cases, result from old infections (non-cluster strains), showing that the occurrence of new cases in the country originates predominantly from endogenous reactivation.

In this study, patients were from a heterogeneous group of people concentrated in the capital city, the Greater Metropolitan Region of Salvador and other towns in the state, in addition to two patients living in another state (São Paulo). This finding shows the mobility of the population-genetic characteristics of tuberculosis between different regions, so providing a contribution to implementing adequate measures in cases of recent infection as well as reactivation of an old infection.

One of the limitations of this study is that, due to the small sample size, it was not possible to obtain a statistically significant association between the formation of cluster patterns and the factors analyzed. Another limitation refers to the fact that the findings on the proportion of cluster patterns may be affected by the incidence of $\mathrm{TB}$, by the heterogeneous nature of the population and by the sampling fraction included in the study. An analysis of these aspects would contribute towards obtaining a more accurate calculation of recent infection in a given community 6,10 .

Despite these limitations, a wide genetic diversity was found in the strains of $M$. tuberculosis analyzed in TB patients in this referral hospital in the city of Salvador. Further studies should be carried out to acquire more data on this subject in Salvador and enable the investigation into associations between the various co-variables and the proportion of cluster strains in this city. 
Figure 1

Dendrogram representing the different RFLP patterns found in isolates of $M$. tuberculosis from patients receiving care at a referral hospital, according to the identification number of the sample, date of isolation, sex, age, place of residence and treatment regimen. Salvador, Bahia State, Brazil.

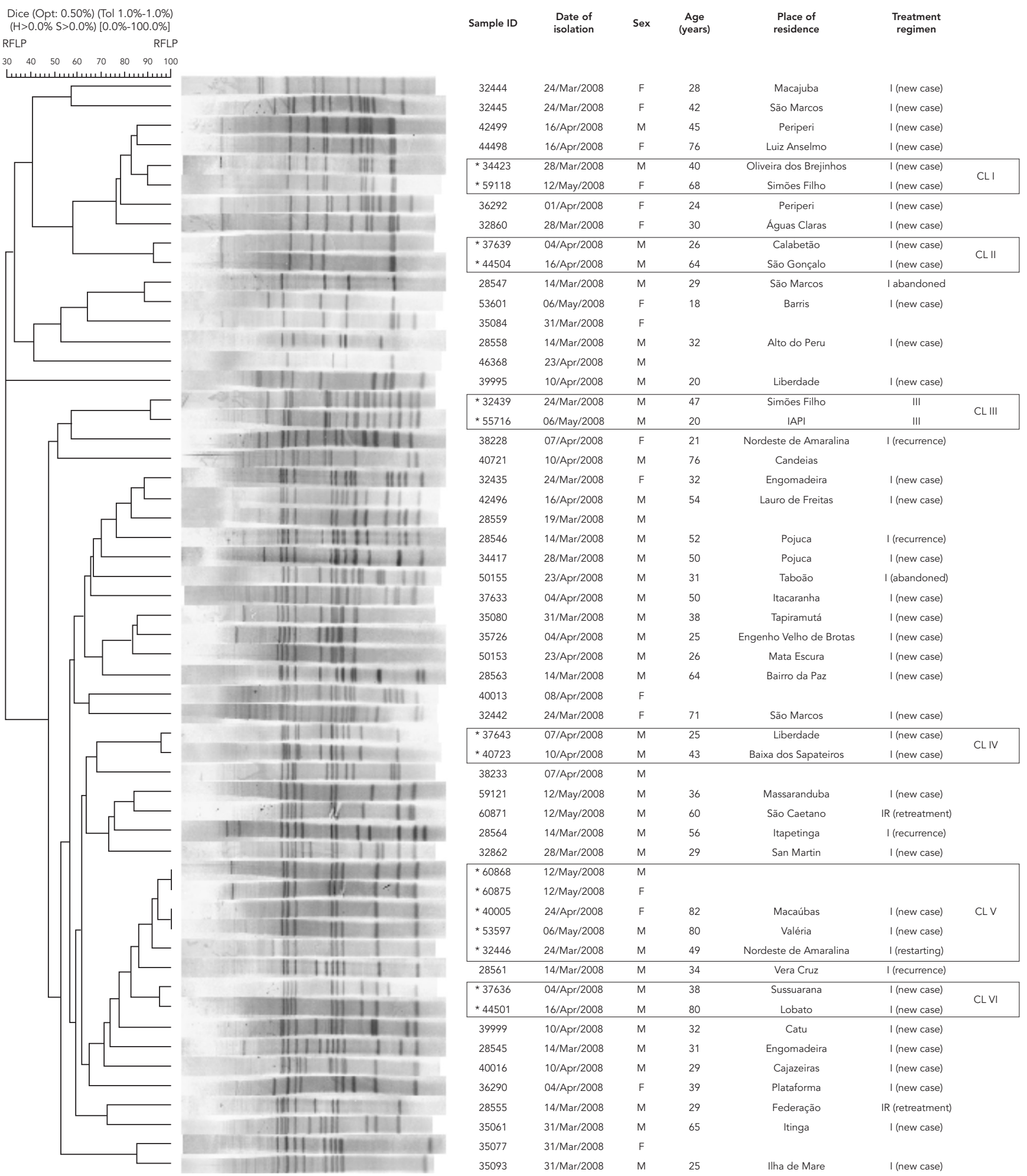




\section{Resumo}

Este é o primeiro estudo realizado na Bahia, Brasil, visando à descrição da estrutura da população genética circulante do Mycobacterium tuberculosis na cidade de Salvador. Um total de 56 casos confirmados de tuberculose pulmonar, identificados entre março e junho de 2008, foi analisado pelo método Restriction Fragment Lenght Polymorphism (IS6110-RFLP). A população de estudo foi caracterizada como a maioria do sexo masculino (71,43\%), idade acima de 30 anos (68,75\%). Quarenta e um isolados $(73,21 \%)$ com padrão único, enquanto 15 (26,75\%) apresentaram padrões agrupáveis, formando seis clusters. A alta taxa de diversidade das cepas de $\mathrm{M}$. tuberculosis observada é mais sugestiva de reativação endógena do que transmissão recente.

Tuberculose; Epidemiologia Molecular; Variação Genética; Mycobacterium tuberculosis

\section{Contributors}

A. C. N. Silva, J. N. Reis, S. M. Pereira, E. L. A. Mota, and M. G. Reis participated in the article's conception, data analysis and interpretation, writing of the article, relevant critical review of the intellectual content, and final approval of the version for publication. L. Ferrazoli collaborated in the conception, data analysis and interpretation, writing of the article, and critical review of the intellectual content. V. Simonsen and T. M. A. Carmo contributed to the article's conception and data interpretation.

\section{Acknowledgments}

Technical team of the Specialist Hospital Octavio Mangabeira/the Secretary of Health of the State of Bahia (HEOM/SESAB), the Directorship of Epidemiological Surveillance (DIVEP/SESAB), the Adolf Lutz Institute/ the Secretary of Health of the State of São Paulo (IAL/ SES-SP) the Gonçalo Muniz Research Foundation/the Oswaldo Cruz Foundation, (CpGM/Fiocruz) for collaborating with the methodology of this study. To the National Health Surveillance Agency (ANVISA) for their financial support.

\section{References}

1. World Health Organization. WHO report 2002: global tuberculosis control. http://www.who.in to/gtb/publications/index.htm (accessed on 02/ Dec/2007).

2. Secretaria de Vigilância em Saúde, Ministério da Saúde. Situação da tuberculose no Brasil. http:// www.saude.gov.br/svs/tuberculose (accessed on 21/Nov/2007).

3. Ferrazoli L, Palaci M, Marques LRM, Jamal LF, Afiune JB, Chimara E, et al. Transmission of tuberculosis in an endemic urban setting in Brazil. Int J Tuberc Lung Dis 2000; 4:18-25.

4. Coordenação Geral de Laboratórios de Saúde Pública, Departamento de Vigilância Epidemiológica, Centro de Referência Prof. Hélio Fraga, Secretaria de Vigilância em Saúde, Ministério da Saúde. Cultura. In: Coordenação Geral de Laboratórios de Saúde Pública, Departamento de Vigilância Epidemiológica, Centro de Referência Prof. Hélio Fraga, Secretaria de Vigilância em Saúde, Ministério da Saúde. Manual de bacteriologia da tuberculose. 3a Ed. Rio de Janeiro: Centro de Referência Prof. Hélio Fraga; 2005. p. 59-74.

5. van Embden JD, Cave MD, Crawford JT, Dale JW, Eisenach KD, Gicquel B, et al. Strain identification of Mycobacterium tuberculosis by DNA fingerprinting: recommendations for a standardized methodology. J Clin Microbiol 1993; 31:406-9.

6. Fandinho FC, Kritski AL, Hofer C, Conde Junior H, Ferreira RM, Saad MH, et al. RFLP patterns and risk factors for recent tuberculosis transmission among hospitalized tuberculosis patients in Rio de Janeiro, Brazil. Trans R Soc Trop Med Hyg 2000; 94:271-5.

7. Borges M, Cafrune PI, Possuelo LG, Valim ARM, Ribeiro MO, Rossetti MLR. Análise molecular de cepas de Mycobacterium tuberculosis provenientes de um centro de saúde ambulatorial em Porto Alegre. J Bras Pneumol 2004; 30:448-54.

8. Gutiérrez MC, Vincent V, Aubert D, Bizet J, Gaillot O, Lebrun L. Molecular fingerprinting of Mycobacterium tuberculosis and risk factors for tuberculosis transmission in Paris, France, and surrounding area. J Clin Microbiol 1998; 36:486-92.

9. Small PM, Hopewell PC, Singh SP, Paz A, Parsonnet J, Ruston DC, et al. The epidemiology of tuberculosis in San Francisco. Apopulation-based study using conventional and molecular methods. N Engl J Med 1994; 330:1703-9.

10. Glynn JR, Vynnycky E, Fine PEM. Influence of sampling on estimates of clustering and recent transmission of Mycobacterium tuberculosis derived from DNA fingerprinting techniques. Am J Epidemiol 1999; 149:366-71.

Submitted on 24/Feb/2011

Approved on 07/Apr/2011 